\title{
Socio-demographic characteristics of participation in the opportunistic German cervical cancer screening programme: results from the EPIC-Heidelberg cohort
}

\author{
David Seidel · Nikolaus Becker · Sabine Rohrmann • \\ Katharina Nimptsch · Jakob Linseisen
}

\begin{abstract}
Objective To analyse participation in the German cervical cancer screening programme by socio-demographic characteristics.
\end{abstract}

Methods In the EPIC-Heidelberg cohort study 13,612 women aged 35-65 years were recruited between 1994 and 1998. Follow-up questionnaires were used to analyse participation in cervical cancer screening. Subjects were categorised according to age (birth cohort), education, vocational training, employment status, marital status and household size. Associations between socio-demographic characteristics and participation in cervical cancer screening were analysed using multinomial logistic regression.

Results Females of the oldest and middle birth cohort were less likely to be screened compared to the youngest birth cohort. Less-educated women and those with a lowlevel secondary school degree had a decreased likelihood of undergoing screening in comparison to better educated women. Married women and women living in households with four or more persons were more likely to participate in the screening programme than single women or women living alone. Employment status did not modify participation in cervical cancer screening.

Conclusions Knowledge on the characteristics of women with a lower attendance to cervical cancer screening could be used to improve the effectiveness of the current (opportunistic) programme by dedicated health promotion programmes. However, an organized screening programme

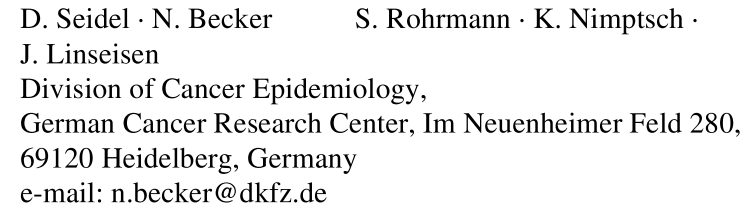

with written invitation of all eligible women would be the preferred option.

Keywords Cervical cancer - Screening · Socio-demographic characteristics · EPIC-Heidelberg · Germany

\section{Introduction}

Cervical cancer is the seventh to eighth most frequent cancer site in Germany with approximately 6,200 incident cases (RKI and GEKID 2008) and 1,600 deaths (Becker and Wahrendorf 1998 and internet update http://www.canceratlas.de) annually. This favourable position for cervical cancer relative to other cancers is largely due to a well established early detection programme. In the pre-screening era of the 1960s, for which incidence is available from the Hamburg cancer registry (Doll et al. 1966), cervical cancer was the second most frequent cancer site among German females after breast cancer with a standardized incidence rate of 34.0 cases per 100,000 women.

Early detection of specific cancers was introduced in 1971 comprising an annual free-of-charge Pap smear from the age of 20 years (Schenck and von Karsa 2000; Becker 2003). This so called "statutory early detection programme" is a self-referring screening policy without invitation and registration system so that individual compliance is unknown. However, from the number of smears evaluated in cytological labs and charged to health insurances, it is known that about 15 millions smears are currently taken, implying a compliance of about $50 \%$ in the target population of 34 million women aged 20 years and above (Fig. 2). Nevertheless, this cross-sectional approach allows for theoretical 3-5 year attendance rates within the wide range of 
$50 \%$ (if exactly the same women came to screening each year) to $100 \%$ (if the remaining $50 \%$ attended screening every other year) and is thus inappropriate for the quantification of this key parameter of screening.

Although it is well-known that organised cervical cancer screening is more effective than opportunistic screening, the German self-referring programme resulted in a strong decline of incidence and mortality by about $80 \%$ since the 1960s (Becker 2003). Nevertheless, it failed the $90 \%$ reduction which was shown to be achievable even with 3-years screening intervals and a narrower target age range (25-64 years) than recommended in Germany (Hakama et al. 1986). Therefore, the question for the reasons of this partial failure arises, and one suggestive factor may be inadequate personal compliance. Thus, efforts to obtain proper data on personal attendance are of major public health relevance.

EPIC-Heidelberg is a large cohort with a periodic active follow-up during which data on participation in the different parts of the early detection programme, including the cervical Pap smear, were collected. The aim of our present analysis was to use these longitudinal data to quantify personal compliance specifically to the early detection policy for cervical cancer in this cohort and to investigate sociodemographic characteristics affecting adherence to the programme.

\section{Materials and methods}

\section{Data material}

The European Prospective Investigation into Cancer and Nutrition (EPIC) is a multicentre prospective cohort study conducted throughout 23 study centres that are located in ten European countries (Denmark, France, Germany, Greece, Italy, the Netherlands, Norway, Spain, Sweden, and the United Kingdom). The aim of EPIC is to investigate relations between nutrition, lifestyle and the incidence of cancer and cause-specific mortality within a long-term follow-up (Riboli and Kaaks 1997). Recruitment began in 1992 and was completed in 2000. The study centres enrolled a total of approximately 520,000 participants aged 20 years and older (Riboli et al. 2002). Two study centres were set up in Germany with one being in the western part of the country (Heidelberg) and the other in the eastern part (Potsdam). The Heidelberg cohort $(N=25,540)$ recruited 13,612 women (aged 35-65) and 11,928 men (aged 40-65) between 1994 and 1998. Though recruitment was based on a random sample of the target age range from the population register, the participation rate of $38.5 \%$ made the observed cohort a self-selected subgroup of the underlying population.
At baseline, study participants received either mailed or handed dietary and lifestyle questionnaires when contacted. The questionnaires contained items on usual diet, physical activity, age at menarche, reproductive history, alcohol and tobacco consumption, medical history and current medication. Concerning medical history, women were, for example, asked whether they had undergone a hysterectomy. In addition, anthropometric measures were ascertained and blood samples taken and stored for laboratory analyses (Riboli and Kaaks 1997). Within the subsequent follow-up phases, study participants were sent follow-up questionnaires in 3 year intervals to update exposure and health status. The follow-up questionnaires contained items on screening for cervical cancer by Pap smear (Boeing et al. 1999b).

All women recruited in the EPIC-Heidelberg cohort study that did not undergo hysterectomy $(N=10,931)$ were eligible for the present analysis. The complete data from the respondents to the questionnaires sent during the first, second, and third follow-up round were available. The first follow-up questionnaire asked women about the history and date of their last cancer screening ("Have you ever attended one of the following early cancer detection examinations? If yes, please state month and year of your most recent examination."). In cases where the last screening was not a Pap smear, individuals were asked whether they had ever been screened for cervical cancer. The questionnaires of the second and third follow-up contained separate items on cervical cancer screening: "Have you ever attended a Pap smear?" and "Have you attended a Pap smear since your previous follow-up?", respectively. In case of a positive response, women were asked to give the month and year of the respective examination. Only females with complete follow-up of cervical cancer screening were retained for the current analysis $(N=9,895)$ and categorised by the number of screenings: none, one, two and three or more. The maximum number of Pap smear dates that could be recorded was three; possible further examinations were not recorded although it is possible that women may have had more tests given that the German cervical cancer screening programme provides annual testing. To reduce potential sources of recall bias, only self-reported Pap smear dates within the determined observation period were considered, where the lower boundary was defined by a subject's recruitment date ( $\geq$ January 1994) and the upper by the response date of the third follow-up questionnaire ( $\leq$ February 2007). Pap smears reported to have been done prior to recruitment or with missing, incomplete or implausible dates were censored from the analysis. Furthermore, Pap smears lying within a 3-month range of another reported smear were considered to be the same event as they are likely to have been repetitions of initially failed ones or clarifications of abnormal smears. 
Statistical methods

Individuals were grouped into two 11-year birth cohorts (1930-1940 and 1941-1951) and one 12-year birth cohort (1952-1963). In addition, subjects were categorised according to five socio-demographic variables: education, vocational training, employment status, marital status and household size. Each of the variables was assigned a score for its different parameter values. Frequency distributions of participation in the cervical cancer screening programme were calculated and grouped by socio-demographic characteristics.

The non-parametric Jonckheere test was applied to the data to test for trends in frequency distributions. Associations between socio-demographic characteristics and participation in none, one, two, and three or more cervical cancer screenings were analysed using multinomial logistic regression models. The group of women who had reported three or more Pap smears was selected as the outcome reference group, which can be seen as an equivalent to nondiseased individuals usually used as the reference group in binary logistic regression. The independent variables birth cohort, education (none, Hauptschule ${ }^{1}$ (or secondary school I), Realschule (or secondary school II) and Gymnasium $^{3}$ (or high school)), vocational training (none, industrial training, vocational/technical school, and technical college ${ }^{4} /$ university $^{5}$ ), employment status (never employed, currently not employed, and employed), marital status (single, widowed, separated, and married), and household size (one person, two persons, three persons, and four or more persons) were integrated as dummy variables into the model and adjusted for follow-up time. Odds ratios (OR) and $95 \%$ confidence intervals (CI) were calculated. The statistical analyses were performed using SAS 9.1 (SAS Institute, Cary, NC, USA).

\section{Results}

\section{Socio-demographic characteristics}

Socio-demographic characteristics of subjects of the female EPIC-Heidelberg cohort are summarized in Table 1. The majority $(43 \%)$ belonged to the youngest birth cohort (1952-1963). Most women reported that they had attended either a high school of 8-9 years $(37 \%)$, which qualifies for

\footnotetext{
${ }^{1}$ Low-level secondary school form of 5 years.

${ }^{2}$ Medium-level secondary school form of 6 years.

${ }^{3}$ High-level secondary school form of 8-9 years; qualifies for admission to technical college/university.

${ }^{4}$ Can be attended after graduation from Gymnasium with at least 8 years of education.

${ }^{5}$ Can be attended after graduation from Gymnasium.
}

Table 1 Socio-demographic and study characteristics of women in the EPIC-Heidelberg cohort study included in the analysis $(N=9,895)$

\begin{tabular}{|c|c|c|}
\hline Socio-demographic characteristics & $\%$ & $N$ \\
\hline \multicolumn{3}{|l|}{ Cohort } \\
\hline 1930-1940 & 21.36 & 2,114 \\
\hline $1941-1951$ & 35.46 & 3,509 \\
\hline $1952-1963$ & 43.17 & 4,272 \\
\hline \multicolumn{3}{|l|}{ Education } \\
\hline None & 0.49 & 48 \\
\hline Secondary school I (Hauptschule) & 34.59 & 3,423 \\
\hline Secondary school II (Realschule) & 28.28 & 2,798 \\
\hline High school (Gymnasium) & 36.64 & 3,626 \\
\hline \multicolumn{3}{|l|}{ Vocational training } \\
\hline None & 9.42 & 932 \\
\hline Industrial training & 27.37 & 2,708 \\
\hline Vocational/technical school & 35.28 & 3,491 \\
\hline Technical college/university & 27.93 & 2,764 \\
\hline \multicolumn{3}{|l|}{ Employment status } \\
\hline Never employed & 0.87 & 86 \\
\hline Currently not employed & 30.20 & 2,988 \\
\hline Employed & 68.93 & 6,821 \\
\hline \multicolumn{3}{|l|}{ Marital status } \\
\hline Single & 12.93 & 1,279 \\
\hline Widowed & 4.30 & 425 \\
\hline Divorced & 10.64 & 1,053 \\
\hline Married & 72.14 & 7,138 \\
\hline \multicolumn{3}{|l|}{ Household size } \\
\hline One person & 14.41 & 1,426 \\
\hline Two persons & 35.24 & 3,487 \\
\hline Three persons & 19.62 & 1,941 \\
\hline$\geq$ Four persons & 30.73 & 3,041 \\
\hline \multicolumn{3}{|l|}{ Observation time in years } \\
\hline$<5$ & 2.74 & 272 \\
\hline 5 to $<7$ & 4.28 & 423 \\
\hline 7 to $<8$ & 23.05 & 2,281 \\
\hline 8 to $<9$ & 41.60 & 4,116 \\
\hline 9 to $<10$ & 26.25 & 2,597 \\
\hline $10+$ & 2.08 & 206 \\
\hline \multicolumn{3}{|c|}{ Having filled-in the follow-up questionnaires of } \\
\hline One follow-up round & 2.7 & 272 \\
\hline Two follow-up rounds & 4.1 & 407 \\
\hline Three follow-up rounds & 89 & 8,823 \\
\hline
\end{tabular}

admission to technical colleges and universities, or a lowlevel secondary school (secondary school I) (35\%), while $28 \%$ of the individuals attained 6 years of education at the medium level (secondary school II). Approximately 55\% of the females had either completed industrial training or an academic programme (technical college/university). About $35 \%$ of the subjects stated that they had completed their 
training at a vocational or technical school and around 10\% reported to have no or incomplete vocational training. The majority of women were married $(72 \%)$ and lived in households of two $(35 \%)$ or four and more persons $(31 \%)$. At recruitment, $69 \%$ of the subjects were employed.

About $90 \%$ of the women have had a follow-up time of 7-10 years and $89 \%$ completed all three follow-up questionnaires.

Attendance to cervical screening and its association with sociodemographic characteristics

The number of females who reported none, one, two, or three or more Pap smears within a median follow-up time of 8.3 years between 1994 and 2007 are shown in Table 2 and Fig. 1. Around $44 \%$ of the women reported to have had three or more cervical cancer screenings in comparison to $30 \%$ who reported having only two and $19 \%$ reporting having had only one screening. Seven percent of the subjects reported that they had not undergone a Pap smear during the observation period. About $46 \%$ of individuals belonging to the youngest birth cohort reported to have had three or more cervical cancer screenings in comparison to $37 \%$ among the oldest birth cohort. In contrast, the fraction of women who had undergone only one or no Pap smear was greatest in the oldest birth cohort. The number of subjects who attended three or more cervical cancer screenings was highest in Gymnasium graduates $(48 \%)$ and lowest in the group without completed secondary school education $(27 \%)$. This latter group also had the highest percentage of individuals who reported one or no Pap smear. Concerning vocational training, a similar picture evolved showing that females with a technical college or university degree had more Pap smears (three or more times) (49\%), whereas those with industrial training or a vocational/technical school degree were more likely to have had two screenings. Accordingly, those without vocational training were more likely to have never participated or to have had only one screening. Among the married respondents, $46 \%$ reported to have had three or more Pap smears in contrast to those reporting to be divorced (42\%), widowed (32\%) or singles $(39 \%)$. The percentage of females who underwent only one or even no such examination was highest in widowed women. Women living in households of four or more persons had reported at least three Pap smears most frequently (49\%) in contrast to those from single households (37\%). The two-sided $P$ values were statistically significant for all trends.

Multivariate regression model for factors affecting cervical screening attendancel

The socio-demographic variables were included in a multinomial logistic regression model with three or more Pap smears as the outcome reference group (Table 3). The results from the regression models showed that females belonging to the oldest birth cohort (1930-1940) were significantly more likely to have had no Pap smear testing (OR $=2.67,95 \%$ CI: 2.07-3.44) or only one testing $(\mathrm{OR}=1.32$, 95\% CI: 1.09-1.60) during the observation interval in comparison to individuals of the youngest birth cohort. Less-educated women were significantly more likely to have had no screening $(\mathrm{OR}=2.52$, 95\% CI: $1.03-$ $6.19)$ or to be screened only once $(\mathrm{OR}=2.69,95 \% \mathrm{CI}$ : 1.19-6.11). Those with a completed secondary school I degree were more likely to undergo no screening $(\mathrm{OR}=1.25,95 \% \mathrm{CI}: 0.92-1.68)$ or one screening $(\mathrm{OR}=1.66$, 95\% CI: 1.34-2.07) in comparison with the highest education group. The likelihood of having attended no, one and two screenings among subjects that had reported a secondary school II degree was generally comparable to those with a high school education level. In line with the above findings, vocationally non-trained females were significantly more likely to have attended no cervical cancer screening $(\mathrm{OR}=2.24,95 \% \mathrm{CI}: 1.55-3.22)$ or only one $(\mathrm{OR}=1.85,95 \% \mathrm{CI}: 1.41-2.43)$ or two $(\mathrm{OR}=1.64,95 \%$ CI: 1.31-2.06) screenings for cervical cancer in comparison to those with a technical college or university level education. No significant associations were found for employment status. Single women were more likely to have not participated in cervical cancer screening $(\mathrm{OR}=1.62,95 \%$ CI: 1.19-2.20). The odds for seeking one and two screenings were smaller but also significantly higher than for married women. Widowed females were more likely to report no screening ( $\mathrm{OR}=1.42$ ), having been screened only once $(\mathrm{OR}=1.45)$ or twice $(\mathrm{OR}=1.32)$ compared to married women with both latter estimates being of borderline significance. The effect of household size was assessed with households with four or more persons as the reference and showed statistical significance for individuals living in oneperson households ( $\mathrm{OR}=1.57,95 \% \mathrm{CI}$ : $1.10-2.24)$ or three-person households ( $\mathrm{OR}=1.32,95 \% \mathrm{CI}: 1.01-1.71)$.

\section{Discussion}

The present analysis showed that about $44 \%$ of the female EPIC-Heidelberg cohort members attended cervical cancer screening at least three times within an average 8.3 years of observation, $74 \%$ at least twice and $93 \%$ at least once. Seven percent did not attend screening within these years. Attendance was strongly associated with socio-demographic characteristics, especially women's age, educational attainment, and vocational training. The associations with the independent variables marital status and household size were somewhat weaker, and no significant association was observed to employment status. 
Table 2 Odds ratios (OR) and 95\% confidence intervals $(95 \%$ CI) describing the likelihood of females to have had none $(\mathrm{Pap}=0)$, one $(\mathrm{Pap}=1)$, or two $(\mathrm{Pap}=2)$ Pap smear tests as compared to $\geq$ three Pap smear tests between 1994 and 2007

( $\mathrm{N}=9,895)$ by socio-demographic characteristics

\begin{tabular}{|c|c|c|c|c|}
\hline $\begin{array}{l}\text { Socio-demographic } \\
\text { characteristics }\end{array}$ & $\begin{array}{l}\text { Pap }=0 \\
n \\
\text { OR } \\
(95 \% \mathrm{CI})\end{array}$ & $\begin{array}{l}\text { Pap = } 1 \\
n \\
\text { OR } \\
(95 \% \mathrm{CI})\end{array}$ & $\begin{array}{l}\text { Pap = } 2 \\
n \\
\text { OR } \\
(95 \% \mathrm{CI})\end{array}$ & $\begin{array}{l}\text { Pap } \geq 3 \\
n \\
\text { Reference } \\
-\end{array}$ \\
\hline Overall & 726 & 1,848 & 2,969 & 4,352 \\
\hline Cohorts & & & & \\
\hline 1930-1940 & $\begin{array}{l}285 \\
2.67 \\
(2.07-3.44)\end{array}$ & $\begin{array}{l}444 \\
1.32 \\
(1.09-1.60)\end{array}$ & $\begin{array}{l}599 \\
1.02 \\
(0.87-1.19)\end{array}$ & $\begin{array}{l}786 \\
1 \\
-\end{array}$ \\
\hline $1941-1951$ & $\begin{array}{l}242 \\
1.45 \\
(1.18-1.80)\end{array}$ & $\begin{array}{l}635 \\
1.05 \\
(0.91-1.20)\end{array}$ & $\begin{array}{l}1,046 \\
0.97 \\
(0.86-1.08)\end{array}$ & $\begin{array}{l}1,586 \\
1 \\
-\end{array}$ \\
\hline 1952-1963 (reference) & $\begin{array}{l}199 \\
1 \\
-\end{array}$ & $\begin{array}{l}769 \\
1 \\
-\end{array}$ & $\begin{array}{l}1,324 \\
1 \\
-\end{array}$ & $\begin{array}{l}1,980 \\
1 \\
-\end{array}$ \\
\hline Education & & & & \\
\hline None & $\begin{array}{l}10 \\
2.52 \\
(1.03-6.19)\end{array}$ & $\begin{array}{l}15 \\
2.69 \\
(1.19-6.11)\end{array}$ & $\begin{array}{l}10 \\
0.93 \\
(0.40-2.18)\end{array}$ & $\begin{array}{l}13 \\
1 \\
-\end{array}$ \\
\hline Secondary school I & $\begin{array}{l}314 \\
1.25 \\
(0.92-1.68)\end{array}$ & $\begin{array}{l}744 \\
1.66 \\
(1.34-2.07)\end{array}$ & $\begin{array}{l}1,051 \\
1.10 \\
(0.92-1.30)\end{array}$ & $\begin{array}{l}1,314 \\
1 \\
-\end{array}$ \\
\hline Secondary school II & $\begin{array}{l}189 \\
1.03 \\
(0.76-1.39)\end{array}$ & $\begin{array}{l}494 \\
1.19 \\
(0.96-1.48)\end{array}$ & $\begin{array}{l}821 \\
0.90 \\
(0.76-1.06)\end{array}$ & $\begin{array}{l}1,294 \\
1 \\
-\end{array}$ \\
\hline High school (reference) & $\begin{array}{l}213 \\
1 \\
-\end{array}$ & $\begin{array}{l}595 \\
1 \\
-\end{array}$ & $\begin{array}{l}1,087 \\
1 \\
-\end{array}$ & $\begin{array}{l}1,731 \\
1 \\
-\end{array}$ \\
\hline Vocational training & & & & \\
\hline None & $\begin{array}{l}123 \\
2.24 \\
(1.55-3.22)\end{array}$ & $\begin{array}{l}248 \\
1.85 \\
(1.41-2.43)\end{array}$ & $\begin{array}{l}278 \\
1.64 \\
(1.31-2.06)\end{array}$ & $\begin{array}{l}283 \\
1 \\
-\end{array}$ \\
\hline Industrial training & $\begin{array}{l}200 \\
1.25 \\
(0.89-1.74)\end{array}$ & $\begin{array}{l}513 \\
0.95 \\
(0.75-1.20)\end{array}$ & $\begin{array}{l}828 \\
1.21 \\
(1.00-1.46)\end{array}$ & $\begin{array}{l}1,167 \\
1.00 \\
-\end{array}$ \\
\hline $\begin{array}{l}\text { Vocational/technical } \\
\text { school }\end{array}$ & $\begin{array}{l}244 \\
1.07 \\
(0.78-1.46)\end{array}$ & $\begin{array}{l}633 \\
0.98 \\
(0.78-1.21)\end{array}$ & $\begin{array}{l}1,068 \\
1.22 \\
(1.03-1.44)\end{array}$ & $\begin{array}{l}1,546 \\
1.00 \\
-\end{array}$ \\
\hline $\begin{array}{l}\text { Technical college/ } \\
\text { university(reference) }\end{array}$ & $\begin{array}{l}159 \\
1 \\
-\end{array}$ & $\begin{array}{l}454 \\
1 \\
-\end{array}$ & $\begin{array}{l}795 \\
1 \\
-\end{array}$ & $\begin{array}{l}1,356 \\
1 \\
-\end{array}$ \\
\hline Employment status & & & & \\
\hline Never employed & $\begin{array}{l}10 \\
1.18 \\
(0.56-2.47)\end{array}$ & $\begin{array}{l}21 \\
1.19 \\
(0.66-2.15)\end{array}$ & $\begin{array}{l}21 \\
0.82 \\
(0.47-1.43)\end{array}$ & $\begin{array}{l}34 \\
1 \\
-\end{array}$ \\
\hline Currently not employed & $\begin{array}{l}277 \\
1.08 \\
(0.89-1.30)\end{array}$ & $\begin{array}{l}590 \\
1.03 \\
(0.90-1.19)\end{array}$ & $\begin{array}{l}868 \\
0.99 \\
(0.88-1.11)\end{array}$ & $\begin{array}{l}1,253 \\
1 \\
-\end{array}$ \\
\hline
\end{tabular}


Table 2 continued

\begin{tabular}{|c|c|c|c|c|}
\hline \multirow[t]{3}{*}{$\begin{array}{l}\text { Socio-demographic } \\
\text { characteristics }\end{array}$} & $\begin{array}{l}\text { Pap }=0 \\
n\end{array}$ & $\begin{array}{l}\text { Pap = } 1 \\
n\end{array}$ & $\begin{array}{l}\text { Pap }=2 \\
n\end{array}$ & $\begin{array}{l}\text { Pap } \geq 3 \\
n\end{array}$ \\
\hline & OR & OR & OR & Reference \\
\hline & $(95 \% \mathrm{CI})$ & $(95 \% \mathrm{CI})$ & $(95 \% \mathrm{CI})$ & - \\
\hline \multirow[t]{3}{*}{ Employed (reference) } & 439 & 1,237 & 2,080 & 3,065 \\
\hline & 1 & 1 & 1 & 1 \\
\hline & - & - & - & - \\
\hline \multicolumn{5}{|l|}{ Marital status } \\
\hline \multirow[t]{3}{*}{ Single } & 109 & 271 & 400 & 499 \\
\hline & 1.62 & 1.57 & 1.23 & 1 \\
\hline & $(1.19-2.20)$ & $(1.26-1.95)$ & $(1.02-1.48)$ & - \\
\hline \multirow[t]{3}{*}{ Widowed } & 56 & 100 & 133 & 136 \\
\hline & 1.42 & 1.45 & 1.32 & 1 \\
\hline & $(0.98-2.05)$ & $(1.06-1.96)$ & $(1.01-1.72)$ & - \\
\hline \multirow[t]{3}{*}{ Divorced } & 71 & 218 & 327 & 437 \\
\hline & 1.04 & 1.31 & 1.14 & 1 \\
\hline & $(0.77-1.41)$ & $(1.07-1.61)$ & $(0.97-1.36)$ & - \\
\hline \multirow[t]{2}{*}{ Married } & 490 & 1,259 & 2,109 & 3,280 \\
\hline & 1.00 & 1.00 & 1.00 & 1 \\
\hline \multicolumn{5}{|l|}{ Household size } \\
\hline \multirow[t]{3}{*}{ One person } & 143 & 317 & 442 & 524 \\
\hline & 1.57 & 1.09 & 1.14 & 1 \\
\hline & $(1.10-2.24)$ & $(0.85-1.40)$ & $(0.93-1.41)$ & - \\
\hline \multirow[t]{3}{*}{ Two persons } & 310 & 641 & 1,047 & 1,489 \\
\hline & 1.28 & 0.92 & 1.04 & 1 \\
\hline & $(1.00-1.64)$ & $(0.78-1.08)$ & $(0.91-1.19)$ & - \\
\hline \multirow[t]{3}{*}{ Three persons } & 136 & 376 & 572 & 857 \\
\hline & 1.32 & 1.14 & 1.04 & 1 \\
\hline & $(1.01-1.71)$ & $(0.96-1.35)$ & $(0.90-1.19)$ & - \\
\hline \multirow[t]{2}{*}{$\geq$ Four persons } & 137 & 514 & 908 & 1,482 \\
\hline & 1.00 & 1.00 & 1.00 & 1 \\
\hline
\end{tabular}

Basically, the longitudinal approach with a relatively long observational period and the high participation rate in the follow-ups make the EPIC-Heidelberg cohort a well-suited tool to investigate personal participation habits in the German early detection programme and their socio-demographic determinants. However, this approach to quantifying attendance has limitations. Firstly, by pooling the responses of the study participants from all three follow-ups, at most three Pap smear dates were observed for the period 1994-2007. The mean observational time of individuals included in the analysis was 8.30 years (standard deviation 1.35) and, thus, if females underwent annual Pap screening, more than twice as many smears than reported could have occurred. However, it is likely that those individuals who are classified as having participated three times or more can be assumed to regularly attend cervical cancer screening, while none or once participation clearly indicates irregular and suboptimal compliance.

Secondly, the analysis is based on self-reports. In a study that examined differences between self-reported screening and information from health care providers (Gordon et al. 1993), women tended to over-report their utilisation of screening as well as to underreport time periods that have passed since their last screening. Therefore, the observed compliance might be an overestimation.

Most importantly, although EPIC-Heidelberg is a population-based cohort, our findings may not be representative of the female population of Germany for two reasons: firstly, the participation rate of $38.5 \%$ and the sociodemographic profile of the cohort members indicate a considerable self-selection bias towards upper social classes (Boeing et al. 1999a). Thus, the proportion of women married or living in partnerships is higher $(72 \%)$ than in the 


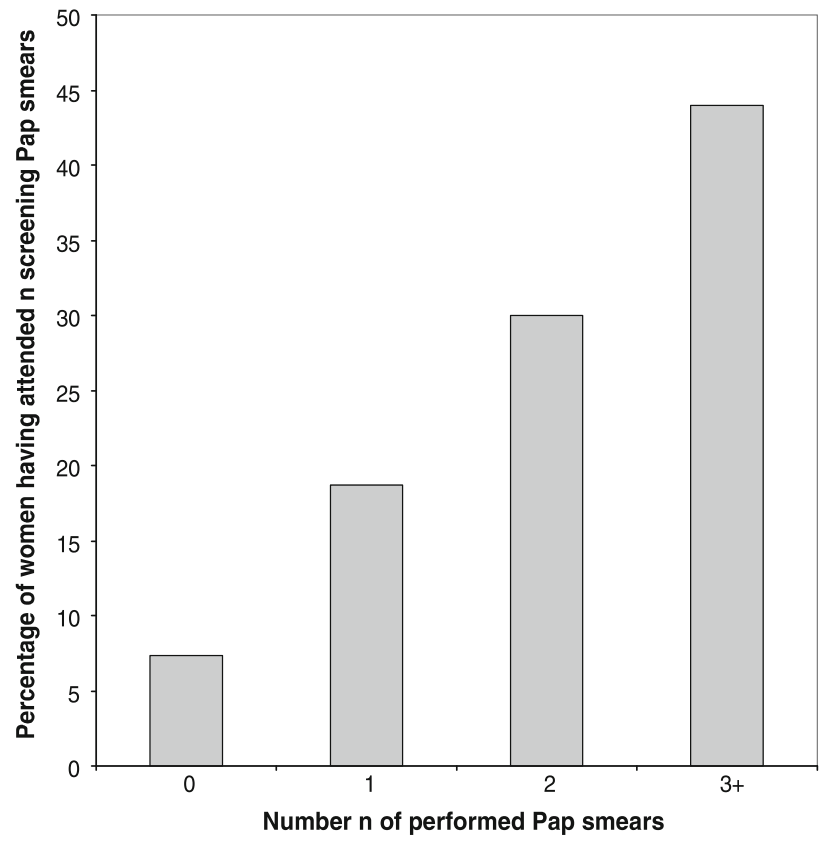

Fig. 1 Percentage of women having attended no, one, two or more Pap smears within their observation time $(N=9,895)$

Federal State (about $60 \%$ ), and the proportion of women in employment is slightly higher (69\%) than in the Federal State (about $65 \%$, Statistical Office of the Federal State of Baden-Württemberg, respectively). In addition, the cohort was recruited from the city of Heidelberg and the surrounding communities, and it is known that women living in metropolitan areas are more likely to be screened (Scheffer et al. 2006). We attempted to control for these limitations by stratifying on social status as indicated by education. Using education as indicator for social status may itself be suboptimal. Nevertheless, it is frequently used in German epidemiological research, since, for example, questions on income are usually a sensitive issue.

Regarding the interpretation of the observed results in comparison to other investigations and other countries, it has to be taken into account that the German early detection policy is based on annual Pap smears and does, thus, not follow the international recommendations of screening intervals of 3-5 years. Low participation in the sense of this policy (see Fig. 2) is, thus, not necessarily too low in the sense of the scientific results on effective screening intervals.

In a recent study on screening participation in a large German city (Klug et al. 2005), more than $80 \%$ of the included individuals $(n=532)$ had reported to be regularly screened for cervical cancer. This figure is much higher than the $44 \%$ of women in our cohort reporting three or more Pap smear tests, but may, however, be itself an overestimation, since only $36 \%$ of the randomly selected subjects filled-in the questionnaire and might represent the more health-conscious fraction of the selected people.

In contrast to the mentioned discrepancy in the observed attendance to screening between different investigations, the associations with socio-demographic characteristics appear to be quite consistent with other national as well as international reports: we found screening attendance related to age as described by Scheffer et al. (2006) for Germany. Attendance of young women was higher than that of older women, middle age groups followed no clear pattern.

Screening attendance was additionally related to education and vocational training consistent to other national (Scheffer et al. 2006) and international results reported from Australia (Taylor et al. 2001) and the USA (Coughlin et al. 2006; Andrykowski et al. 2007) showing higher attendance among women with better education or vocational training.
Fig. 2 Attendance to the German statutory early detection programme among males and females in percent of the eligible population (1991-2005).

Source: L. Altenhofen, Central Research Institute of Ambulatory Health Care in Germany, personal communication

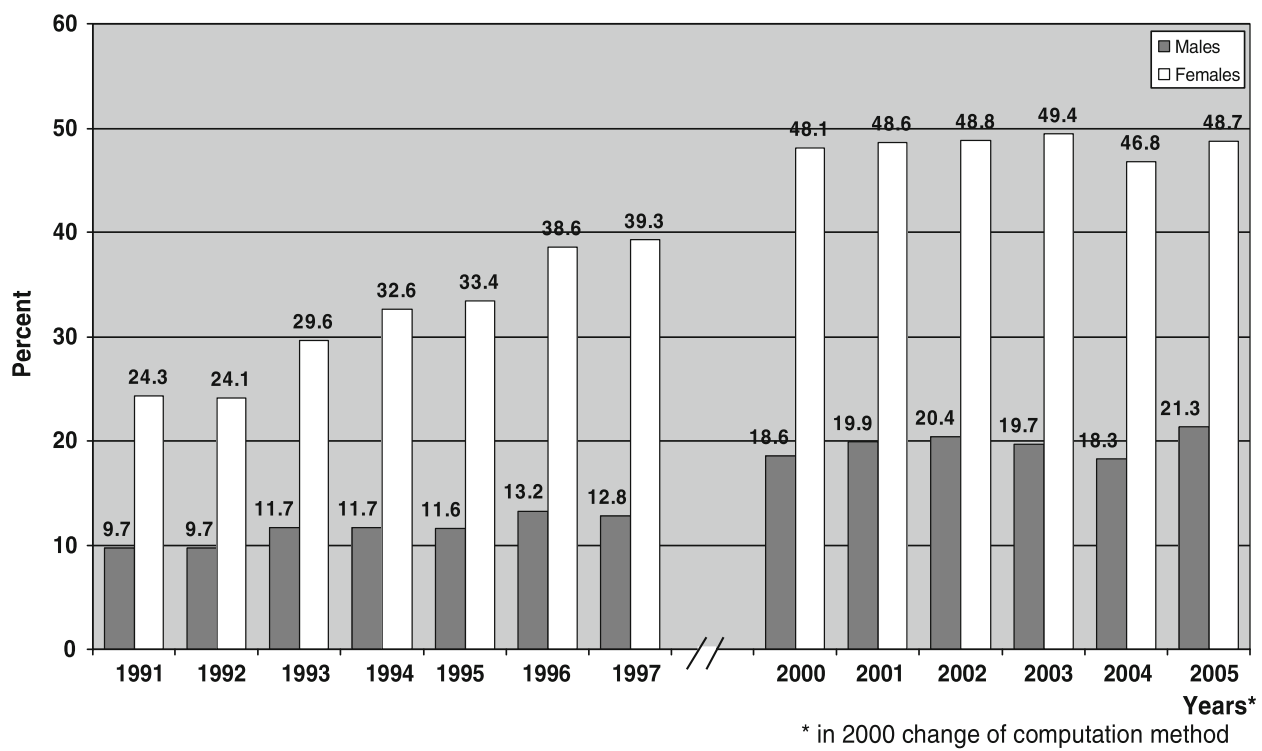


Again, in accordance to other national data (Scheffer et al. 2006), no clear association of screening attendance with employment status was found, but occupational position was associated with screening. Women in higher ranked positions attended screening programmes more frequently than women working in lower ranked positions.

Married women seem to participate more regularly in screening than non-married women in our study as well as in the mentioned report from Scheffer et al. (2006) for Germany and in accordance to Swedish data (Rodvall et al. 2005).

Income level as direct indicator for social status has been related to cervical cancer screening attendance (Coughlin et al. 2006, Taylor et al. 2001). As mentioned in the "Statistical methods", income data are mostly not available in German epidemiological studies including EPIC-Heidelberg. Thus, socio-demographic characteristics as education, employment position, marital status as described above must be taken as indirect indicators.

Based on the results of the present study, the effectiveness of the current (opportunistic) screening programme in Germany could be improved by specific activities to motivate these subgroups of women with the lowest attendance. However, the proportion of women with low educational level who had two Pap smears or more within a median observation time of 8.3 years is about $70 \%$ (excluding the extremely small group of women without education), and about $78 \%$ for those in the high educational level group. Thus, the difference in cervical cancer screening attendance between women with low and high educational level is distinct but limited to $<10 \%$. Furthermore, having two smears within 8.3 years is not so different from, for example, the Dutch programme, which has recently increased the intervals from 3 to 5 years (Rebolj et al. 2006), or the Finnish programme with 5-years intervals (Anttila and Nieminen (2000)). Both programmes are known to perform well since the participation and the quality of the programmes is high. Dedicated programmes for promoting attendance of lower social classes to primary or secondary prevention are frequently recommended, however, convincing practical approaches are still lacking.

Alternatively, realization of the European recommendations for quality-assured cervical cancer screening (European Commission 2008) appears to be more promising. It implies to restructure the German policy to an organised screening programme with written invitation and quality assurance according to the European Guidelines. The written invitation would cover the entire population including those social groups with hitherto low attendance but also those $20 \%$ of higher social classes who failed regular attendance so far. The 3-year intervals, combined with quality-assurance of the smear evaluation, would increase the effectiveness of the programme and even decrease its costs.
Scientific evaluations have shown that the effectiveness of organised cervical screening is higher than that of opportunistic screening (IARC 2005). The present evaluation indicates specific failures of the opportunistic German cervical cancer screening policy that could be resolved by a change to organised screening.

Acknowledgments We thank all women of the EPIC-Heidelberg cohort study for providing the information used for the present study.

\section{References}

Andrykowski MA, Zhang M, Pavlik EJB, Kryscio RJ (2007) Factors associated with return for routine annual screening in an ovarian cancer screening program. Gynecol Oncol 104:695-701. doi:10.1016/j.ygyno.2006.10.044

Anttila A, Nieminen P (2000) Cervical cancer screening programme in Finland. Eur J Cancer 36:2209-2214

Becker N (2003) Epidemiological aspects of cancer screening in Germany. J Cancer Res Clin Oncol 129:691-702

Becker N, Wahrendorf J (1998) Atlas of Cancer Mortality in Germany 1981-1990, 3rd edn. Springer, Berlin

Boeing H, Korfmann A, MM Bergmann, Recruitment procedures of EPIC-Germany (1999a) European Investigation into Cancer and Nutrition. Ann Nutr Metab 43:205-215

Boeing H, Wahrendorf J, Becker N (1999b) EPIC-Germany-a source for studies into diet and risk of chronic diseases. Ann Nutr Metab 43:195-204

Coughlin SS, King J, Richards TB, Ekwueme DU (2006) Cervical cancer screening among women in metropolitan areas of the United States by individual-level and area-based measures of socioeconomic status, 2000 to 2002. Cancer Epidemiol Biomarkers Prev 15:2154-2159

Doll R, Payne P, Waterhouse J (1966) Cancer incidence in five continents. A technical report. International Union Against Cancer. Springer, Berlin

European Commission (2008) European guidelines for quality assurance in cervical cancer screening, 2nd edn. European Commission, Brussels

Gordon NP, Hiatt RA, Lampert DI (1993) Concordance of self-reported data and medical record audit for six cancer screening procedures. J Natl Cancer Inst 85:566-570

Hakama M, Miller AB, Day NE (1986). Screening for cancer of the uterine cervix. IARC Scientific Publications No. 76. IARC, Lyon

IARC (2005) Cervic cancer screening. IARC handbooks of cancer prevention, vol 10. International Agency for Research on Cancer, Lyon

Klug SJ, Hetzer M, Blettner M (2005) Screening for breast and cervical cancer in a large German city: participation, motivation and knowl edge of risk factors. Eur J Public Health 15:70-77

Rebolj M, van Ballegooijen M, Berkers L-M, Habbema D (2006) Monitoring a national cancer prevention program: successful changes in cervical cancer screening in the Netherlands. Int J Cancer 120:806-812

Riboli E, Kaaks R (1997) The Epic project: rationale and study design. European Prospective Investigation into Cancer and Nutrition. Int J Epidemiol 26:6-14

Riboli E, Hunt KJ, Slimani N, Ferrari P, Norat T, Fahey M, Charrondiere UR et al (2002) European Prospective Investigation into Cancer and Nutrition (EPIC): study populations and data collection. Public Health Nutr 5:1113-1124

RKI (Robert-Koch-Institute), GEKID (Society of the epidemiological cancer registries in Germany) (2008) Cancer in Germany 20032004 (in German). 6. revised version, Berlin 
Rodvall Y, Kemetli L, Tishelman C, Törnberg S (2005) Factors related to participation in a cervical cancer screening programme in urban Sweden. Eur J Cancer Prev 14:459-466

Scheffer S, Dauven S, Sieverding M (2006) Sociodemographic differences in the participation in "early detection of cancer examinations" in Germany-a review. Gesundheitswesen 68:139-146
Schenck U, von Karsa L (2000) Cervical cancer screening in Germany. Eur J Cancer 36:2221-2226

Taylor RJ, Mamoon HA, Morrell SL, Wain GV (2001) Cervical screening by socio-economic status in Australia. Aust N Z J Public Health 25:256-260 